\title{
Sub-occipital ligature knot in a case of long drop suicidal hanging with rare autopsy finding of cervical spine fracture
}

\author{
Pankaj Suresh Ghormade ${ }^{1 *}$, Bedanta Sarma ${ }^{2}$ and Sandeep Gajbhiye ${ }^{3}$
}

\begin{abstract}
Background: Hangman's fracture (Fracture of cervical vertebrae) in hanging is usually described into the context of judicial type of hanging where the individual is dropped from a calculated height with sub-mental or sub-aural position of ligature knot. Such a long drop with typical upper cervical vertebral fracture is a rare entity in a case of suicidal hanging.

Case presentation: We have described such a case where an average built deceased weighing $62 \mathrm{~kg}$ hang himself with a nylon rope by jumping from a branch of tree with a drop length of $6.3 \mathrm{~m}$, which was sufficiently long enough to cause soft tissue injuries, transection of larynx along with fracture and dislocation of cervical spine at C2-C3 level contrary to the fact that position of ligature knot was in sub-occipital area. Hence, this rare case is discussed with reference to the probable mechanism involved in causation of such internal injuries.

Conclusion: In our case of long drop hanging, we found fracture of cervical spine when ligature knot was placed at sub-occipital position which is a rare autopsy finding. We also noticed deep laceration of skin and transection of larynx as extremely rare finding in hanging caused by flexible and blunt nylon rope used as ligature material.
\end{abstract}

Keywords: Hangman's fracture, Long drop, Sub-occipital, Knot, Autopsy, Hanging

\section{Background}

Hanging is a form of death due to constriction of the neck when the force applied is derived from the gravitational drag of the victim's body weight (DiMaio and DiMaio 2001; http://ncrb.nic.in/StatPublications/CII/ CII2015/FILES/Statistics-2015.rev11.pdf). Among all the modes, hanging is the most common method of committing suicide in India according to recent data published by national crime records bureau, government of India (Sauko and Knight 2004).

In most of cases of suicidal hanging, cause of death is due to compression of vasculature and airway. Injury to upper cervical spine, usually at the level of $\mathrm{C} 1-\mathrm{C} 2$ and $\mathrm{C} 2-$ C3 are mostly seen in judicial type of hanging, wherein

\footnotetext{
* Correspondence: pankajforensic@gmail.com

'Department of Forensic Medicine \& Toxicology, All India Institute of Medical Sciences (AllMS) Raipur, AlIMS TATIBANDH, GE ROAD, Raipur, Chhattisgarh C.G-492099, India

Full list of author information is available at the end of the article
}

the body falls from a sufficient distance before suspension (Dolinak and Matshes 2005; Hejna and Bohnert 2013). Hangman's fracture as described by Wood Jones in 1913 involves fracture-dislocation of the 2 nd cervical vertebra as a result of hyperextension and distraction of the neck (Wood-Jones 1913). If the length of drop is several meters, more profound injuries like decapitation (complete/incomplete) can occur (Rothschild and Schneider 1999). Hence, in judicial hanging drop length is calculated according to the height and weight of the individual to prevent decapitation.

Body weight, falling distance and nature of ligature material (elastic/inelastic) are the most important factors in the patho-mechanism of decapitation in long drop suspension (Byard and Gilbert 2017). When a moving body falls with noose around neck, it causes injuries to cervical structures through additional axial traction (deceleration force) and radial shearing forces of the tightening noose. Hence, in hanging cases with long- 
drop, the structures of the neck are injured by strain caused by increased gravitational drag produced by the body's weight.

Herewith we are discussing a case of long drop suicidal hanging by using nylon rope as ligature material with suboccipital position of knot and atypical autopsy findings of fracture-dislocation of upper cervical vertebra as position of the knot was unfavorable to cause such injuries.

\section{Case presentation}

Alongside a running nullah, dead body of deceased, a 62 years old male was found to be in completely hanged position with ligature material as yellow nylon rope. At the spot, dead body was suspended to a branch of tree and at the point of suspension; rope was encircled around it and tied with fixed knots. Height of suspension was about $6.3 \mathrm{~m}$ from the knot (Fig.1). Case was sent for medico legal autopsy in department of Forensic Medicine at Tertiary Care Institute.

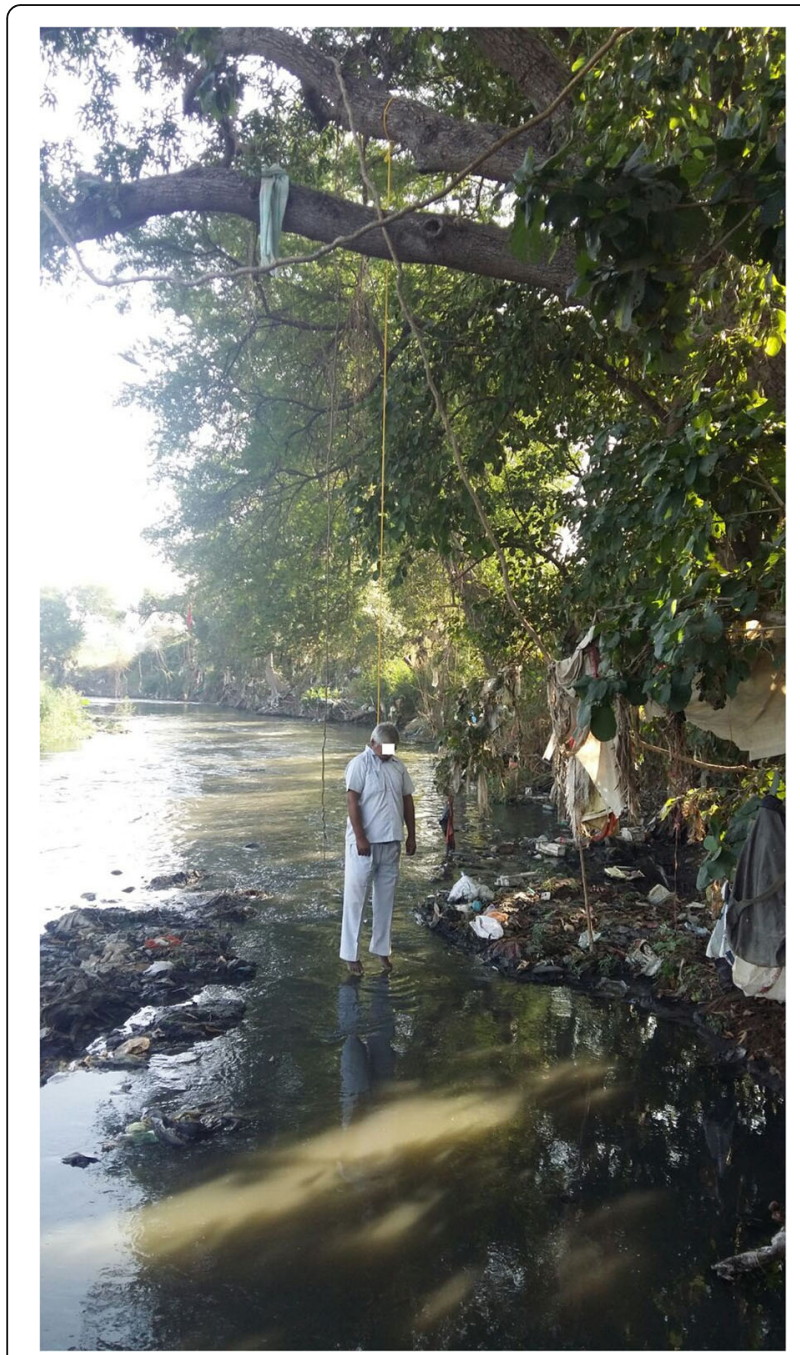

Fig. 1 Findings at site of hanging by deceased

\section{Autopsy findings \\ External findings}

Height \& weight of deceased was $158 \mathrm{~cm} \mathrm{\&} 62 \mathrm{~kg}$, respectively. Eyes were partially open with haziness in corneas. Tongue was found to be clinched in between teeth's. Marks of dried salivary stains caused due to dribbling of saliva were present over chin and upper part of shirt in midline. Rigor mortis was well marked in the whole body. Fixed gloves and stocking type of post mortem lividity was present.

A single loop of yellow nylon rope having circumference $13 \mathrm{~mm}$ was present around the neck in situ, as ligature material. It was tied by two fixed knot which were at sub-occipital region of neck. After removing the ligature material, ligature mark was present over the neck, seen above the level of thyroid cartilage. Its direction was obliquely upwards and backwards and involved antero-lateral sides of neck and extended up to suboccipital region. Length and maximum width of ligature mark were $32 \mathrm{~cm}$ and $3 \mathrm{~cm}$, respectivly.It showed deep laceration of skin over antero-lateral sides of neck, measuring length $13 \mathrm{~cm}$, maximum width and depth $2 \mathrm{~cm} \& 1.7 \mathrm{~cm}$, respectively. Remaining part of ligature mark was grooved pressure abrasion (Fig. 2).

\section{Internal findings}

On dissection of neck, hematoma was present in Sternomastoid muscle bilaterally. Right Sternomastoid muscle was lacerated corresponding to overlying ligature mark. Larynx was transected at Supraglottic region. Thyroid cartilage showed fracture of lamina in its midline. Fracture of left greater cornuae of hyoid bone was present (Fig. 3). On examination of cervical spine, fracture of spine at $\mathrm{C} 2-\mathrm{C} 3$ vertebral level was noticed along with dislocation of $\mathrm{C} 2$ over $\mathrm{C} 3$ vertebra. Underlying spinal cord was lacerated, contused with hemorrhage in surrounding area (Fig. 4). All other visceral organs were

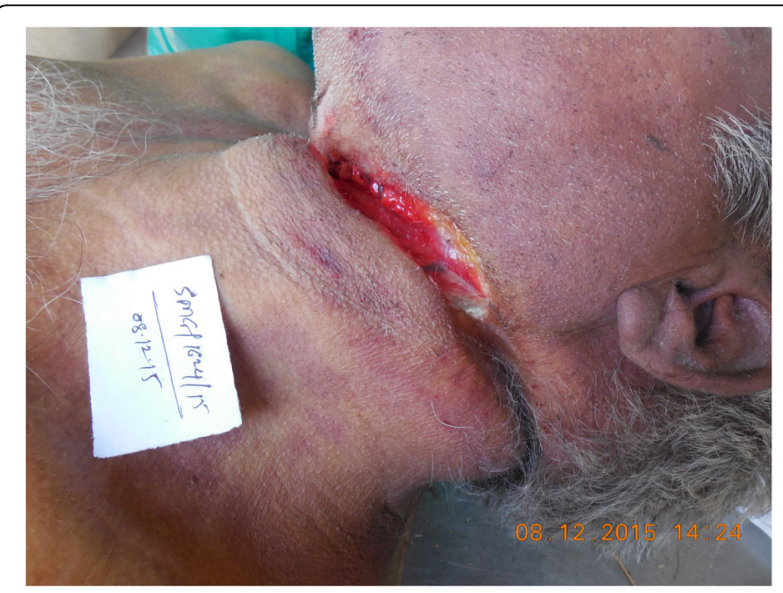

Fig. 2 Atypical pattern of ligature mark injury over neck 


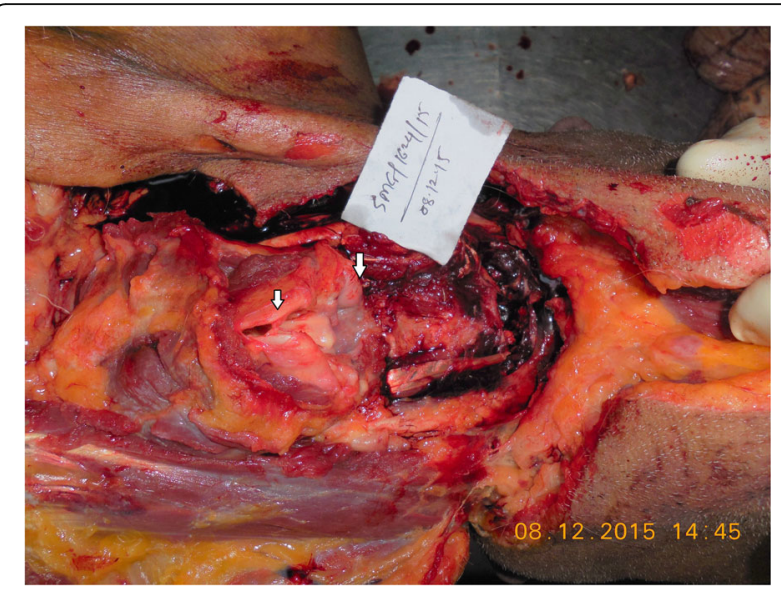

Fig. 3 Findings in larynx and neck

congested. Stomach was filled with partially digested food matter with no characteristic smell. On toxicological analysis, no alcohol or toxic compound detected.

\section{Discussion}

Suicide by long drop hanging is a rare occurrence. These are usually 'short-drops', and the total distance of the drop is less than $0.6-0.9 \mathrm{~m}$. It is uncommon for suicidal hanging to involve a 'long-drop' in which the descent is between 4.3 and $5.2 \mathrm{~m}$ (Hellier and Connolly 2009).

A fall with a noose around the neck is associated with frequent injuries involving local structures as a result of axial traction and radial shearing forces. Victims although suffer a wide range of soft tissue

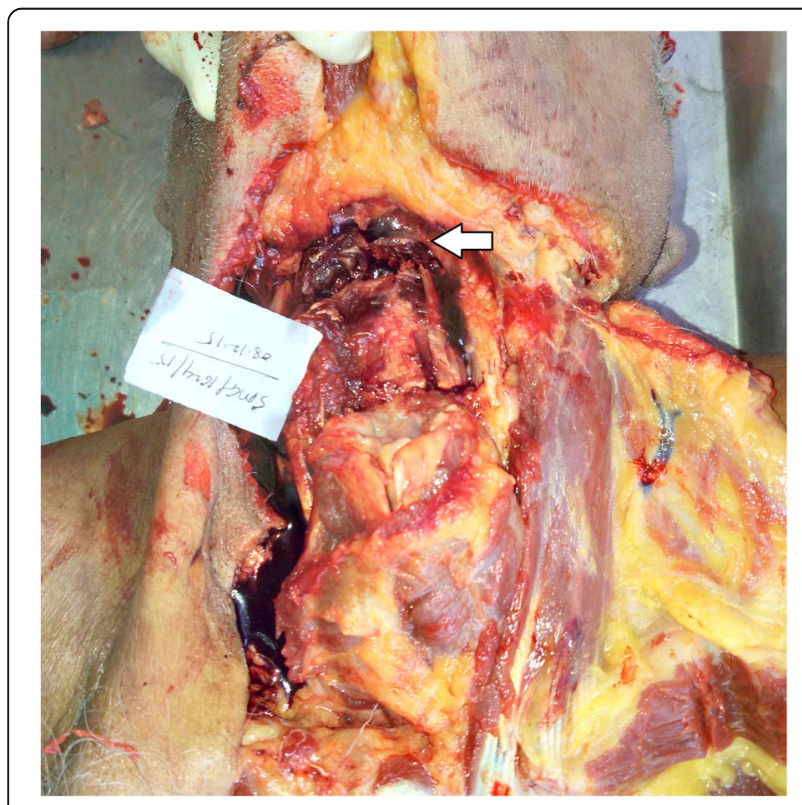

Fig. 4 Findings in cervical spine injuries, fracture of the cervical spine along with spinal cord injuries are unusual in routine hanging. Exact incidence of cervical bony injury following suicidal hanging is not known, and has been observed different in different surveys. But when they occur, they tend to be described with reference to judicial hanging in which the body falls some distance before suspension (Dolinak and Matshes 2005). Long drop suspension, most typified by judicial execution is meant to result in fracture of $\mathrm{C} 2$ and $\mathrm{C} 3$ rather than obstruction of vasculature and airway (Thierauf and Pollak 2008). Typical "Hangman's fracture" i.e. bilateral fracture of $\mathrm{C} 2$ with anterior sublaxation or dislocation of the body due to hyperextension of the neck can be seen in such long drops only (Hellier and Connolly 2009). Fractures may also occur between cervical vertebrae 1-2 or 3-4 (Toro et al 2008; Dedouit et al. 2007). Although, hyperextension has been described by majority of authors as the most common neck movement for causing fracture-dislocation, ante-flexion was also found by few (Zhu et al. 2000). Nikolic \& Zivkovic reported cervical spine injury in a cases of hanging without long-drop pattern with a frequency $3.27 \%$ (Nikolic and Zivkovic 2014). But, in his series all the victims were old aged with severe osteoporotic changes in bones.

If the drop is sufficiently high, it may result in even more profound injuries such as decapitation. When a narrow wire is used, it may lacerate the soft tissue of neck even without a long drop (cheese cutter method). Occurrence of complete or incomplete decapitation can increase by the increasing energy stored as potential energy at the starting position and the characteristics of the rope extended by the hanging body (Toro et al 2008). Such energy can be stored by changing the position in the gravitational field, by changing the shape of the hanging rope and by changing the motion of the hanging body. In a biomechanical experiment, it was found that traction-forces of about 12,000 Newton lead to complete decapitation irrespectively of the diameter of the used halter (Rabl et al. 1995).

In the present case, the deceased felt down from a distance of $6.3 \mathrm{~m}$ before suspension and constriction by the rope. Usually, in such long drops, there is every chance of partial or complete decapitation due to traction force. However, there was laceration of skin over the anterolateral aspect of the neck along with transection of larynx. This rare occurrence in such long drop can be described by the weight of the individual and nature (thick and elastic) of the ligature material. The deceased was an average built person with body weight $62 \mathrm{~kg}$, which was insufficient to cause enough gravitational drag, thus preventing decapitation even after sufficient traction. 


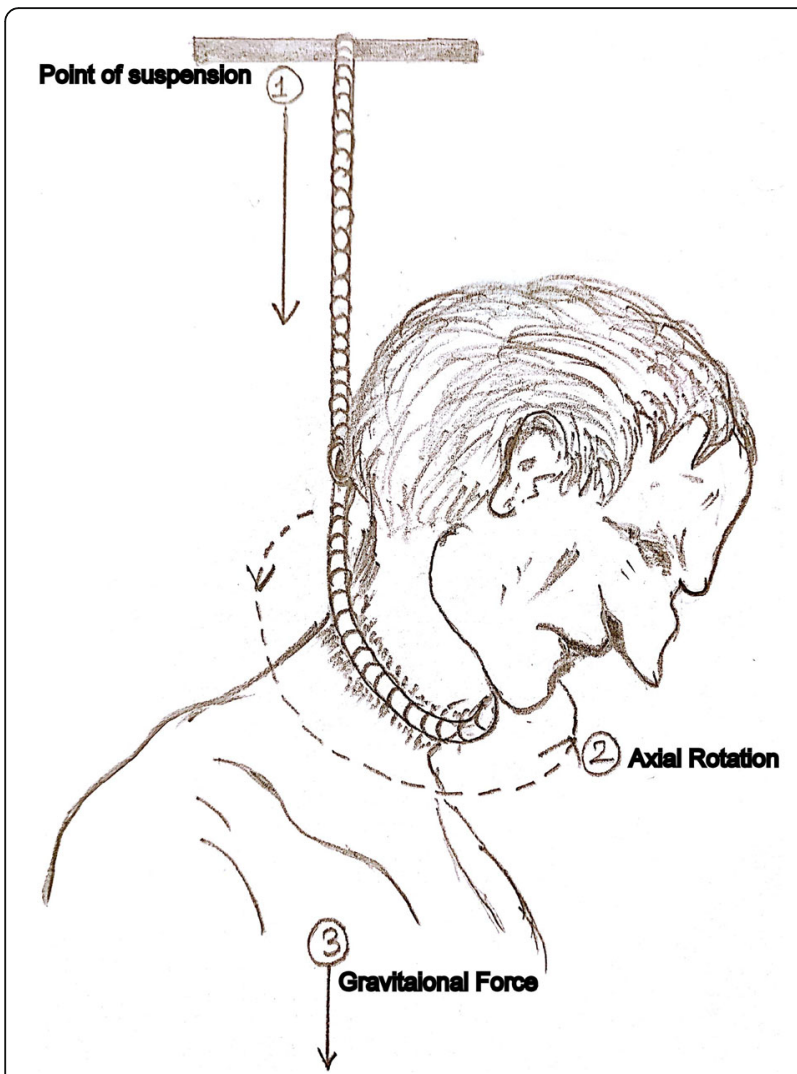

Fig. 5 (Sketch): Mechanism inovlved for findings seen in neck

Fracture and dislocation of cervical vertebra $\mathrm{C} 2$ over C3 was noted in this case. Fracture of cervical vertebra in hanging occurs due to sudden movement of the neck, mostly by hyperextension. Such cases can be explained with respect to the position of knot, along with the drop height. To cause typical Hangman's fracture, ideal position is either sub-mental or sub-aural. However, in our case, the position of the knot was in sub-occipital area and in this scenario cervical spine fracture is unlikely as it causes mostly ante-flexion of neck. Hence, this atypical presentation can be correlated with extreme height of long drop along with sudden drag irrespective of position of knot. Perhaps, the deceased jumped from the branch of the tree after tightening the rope, which is sufficiently high up causing sudden twist of the neck before suspension along with gravitational drag due to positional effect (Fig. 5). This movement at the time of suspension may be responsible for the fracture \& dislocation.

\section{Conclusion}

Fracture of cervical spine in long drop suicidal hanging with sub-mental or sub-aural position of ligature knot is scientifically proven autopsy findings. However, in our case of long drop hanging, we found fracture of cervical spine when ligature knot was in sub-occipital position as a rare autopsy findings. We also noticed deep laceration of skin and transection of larynx as extremely rare finding caused by flexible and blunt nylon rope used as ligature. Hence, further study is required regarding exact patho-mechanism of such incidences to peer deep into such rare occurrences.

\section{Acknowledgements}

We sincerely acknowledge constant support and guidance provided by Dr.A.N.Keoliya, Professor and Head Dept. of Forensic Medicine, IGGMC Nagpur.

\section{Funding}

We wish to confirm that there are no known conflicts of interest associated with this publication and there has been no financial support for this work that could have influenced its outcome.

Availability of data and materials

We do not wish to share our data as references are cited in our case paper.

\begin{abstract}
Author's contributions
We confirm that the manuscript has been read and approved by all named authors and that there are no other persons who satisfied the criteria for authorship but are not listed. We further confirm that the order of authors listed in the manuscript has been approved by all of us. We understand that the Corresponding Author is the sole contact for the Editorial process (including Editorial Manager and direct communications with the office). He is responsible for communicating with the other authors about progress, submissions of revisions and final approval of proofs. We confirm that we have provided a current, correct email address which is accessible by the Corresponding Authors and which has been configured to Accept email from pankajforensic@gmail.com
\end{abstract}

\section{Ethics approval and consent to participate}

Consent for publishing data collected during medico-legal autopsy has been accorded by investigating officer and relatives of the deceased. Institutional ethics committee of IGGMC, Nagpur had reviewed our case paper and approved it as there is no disclosure of identity of any individual.

\section{Consent for publication}

In our case paper, images used are entirely unidentifiable and data described in manuscript does not disclose identity of any individual. Although consent for publication is taken from investigating officer and relatives of the deceased.

\section{Competing interests}

We confirm that we have read Springer Opens Guidelines on competing interests and we declare that none of us have any competing interests in the submitted manuscript.

\section{Publisher's Note}

Springer Nature remains neutral with regard to jurisdictional claims in published maps and institutional affiliations.

\section{Author details}

${ }^{1}$ Department of Forensic Medicine \& Toxicology, All India Institute of Medical Sciences (AlIMS) Raipur, AlIMS TATIBANDH, GE ROAD, Raipur, Chhattisgarh C.G-492099, India. ${ }^{2}$ Department of Forensic Medicine \& Toxicology, Indira Gandhi Government Medical College (IGGMC), Nagpur, Maharashtra 440018, India. ${ }^{3}$ Opposite Hansveni Guest House, At.668 B Karnewar marg, Telipura, Sitabuldi, Nagpur, Maharashtra 440012, India.

Received: 18 October 2017 Accepted: 26 March 2018 Published online: 03 April 2018

\section{References}

Byard RW, Gilbert JD (2017) Suicidal decapitation by hanging-a population-based study. J Forensic Sci:1-3. https://doi.org/10.1111/1556-4029.13638. 
Dedouit F, Tournet G, Becart A, Hedouin V, Gosset D (2007) Suicidal hanging resulting in complete decapitation - forensic, radiological, and anthropological studies: a case report. J Forensic Sci 52(5):1190-1193 DiMaio DJ, DiMaio D (2001) Forensic pathology. CRC Press LLC, New York, pp 229-277

Dolinak D, Matshes EW (2005) Asphyxia- forensic pathology principles and practice, 4th edn. Elsevier Academic Press, London, pp 149-176

Hejna P, Bohnert M (2013) Decapitation in suicidal hanging: vital reaction patterns. J Forensic Sci 58(1):270-277

Hellier C, Connolly R (2009) Cause of death in judicial hanging: a review and case study. Med Sci Law 49:18-26

Nikolic S, Zivkovic V (2014) Cervical spine injuries in suicidal hanging without a long drop-patterns and possible underlying mechanisms of injury: an autopsy study. Forensic Sci Med Path 10(2):193-197

Rabl W, Haid C, Katzgraber F, Walser B (1995) Hanging with decapitation: case report-biomechanics. Arch Kriminol 195(1-2):31-37

Rothschild MA, Schneider V (1999) Decapitation as a result of suicidal hanging. Forensic Sci Int 106(1):55-62

Sauko P, Knight B (2004) Knight's forensic pathology. Edward Arnold Publishers Ltd, London, pp 368-393

Thierauf A, Pollak S (2008) Strangulation (chapter) in: forensic pathology. First edition academic press- Elsevier; 2017:143.

Toro K, Kristof I, Keller E. Incomplete decapitation in suicidal hanging-report of a case and review of the literature. J Forensic Legal Med 15(3):180-184

Wood-Jones F (1913) The ideal lesion produced by judicial hanging. Lancet 181(4662):53

Zhu B, Quan L, Ishida K, Oritani S, Taniguchi M (2000) Decapitation in suicidal hanging-a case report with a review of the literature. Legal Med 2(3):159-152

\section{Submit your manuscript to a SpringerOpen ${ }^{\circ}$ journal and benefit from:}

- Convenient online submission

Rigorous peer review

- Open access: articles freely available online

- High visibility within the field

- Retaining the copyright to your article

Submit your next manuscript at $>$ springeropen.com 